\title{
EDITORIAL
}

\section{Breathing and Cardiovascular Patterns: What can we Learn from Respiratory Exercises?}

\author{
Gabriel Dias Rodrigues ${ }^{1,2}$ (1) \\ Laboratory of Experimental and Applied Exercise Physiology, Department of Physiology and Pharmacology, Fluminense Federal University, ${ }^{1}$ Niterói, RJ - Brazil \\ National Institute for Science \& Technology - INCT Physical (In)activity \& Exercise, CNPq, ${ }^{2}$ Niterói, RJ - Brazil \\ Editorial referring to the article: Increased Maximal Expiratory Pressure, Abdominal and Thoracic Respiratory Expansibility in Healthy Yoga \\ Practitioners Compared to Healthy Sedentary Individuals
}

In the current issue of the International Journal of Cardiovascular Sciences, Fetter and colleagues ${ }^{1}$ found that respiratory movements of the abdominal cavity and rib cage, evaluated by circumferences measurements, were higher in Yoga practitioners than in an age-matched sedentary group. Also, the study confirmed that Yoga practitioners showed higher maximal expiratory strength and lower heart rate at rest than non-practitioners.

Yoga has been recommended as a non-pharmacological therapy to control cardiovascular risk factors. ${ }^{2}$ Respiratory exercises are part of the Yoga program that includes abdominal and rib cage expansion by rhythmic movements. ${ }^{1-3}$ It was demonstrated that four months of Yoga respiratory training improved inspiratory and expiratory muscle strength, forced vital capacity and quality of life in healthy elderly. Another study demostrated that Yoga influenced cardiorespiratory control, affecting the resting sympatho-vagal balance, with a shift from vagal to sympathetic predominance, reflecting a sympathetic withdrawal. ${ }^{3}$ Several disease subsets are marked by autonomic dysfunction characterized by sympathetic overactivity at rest, and in this context, respiratory exercises such as Yoga may be a potential countermeasure.

\section{Keywords}

Breathing; Cardiovascular Diseases; Breathing Exercises; Yoga; Physical Therapy Modalities; Continuity of Patient Care.
As regards respiratory influences on hemodanymic, acute changes in spontaneous respiratory pattern at rest $^{4,5}$ or during orthostatic stress ${ }^{5}$ cause a great impact on cardiovascular and cerebrovascular regulation. These changes seem to be influenced by a combination of neural and non-neural mechanisms, such as changes in heart rate variability, respiratory sinus arrhythmia, ${ }^{4,6}$ and mechanical contributions of the respiratory muscle pump on venous return, stroke volume, and cardiac output. ${ }^{5}$

Inspiratory muscle training (IMT) is another respiratory training modality that was proposed in the current literature as a plausible method to improve respiratory muscle strength in healthy individuals and patients with cardiovascular and respiratory diseases. Recently, it was suggested that IMT is a feasible method to enhance cardiovascular control at rest ${ }^{6-8}$ and post-exercise, ${ }^{6}$ and cerebrovascular and postural control during orthostatic stress ${ }^{9}$ in older women. In particular, IMT reduced postural instability and the time to cerebral blood flow recovery in the initial phase of orthostatic stress, ${ }^{9}$ suggesting that IMT could be a potential intervention to prevent fall accidents in this population.

Therefore, further studies could investigate the impact of novel combinations of breathing maneuvers during respiratory exercise programs, on putative mechanisms of changes in spontaneous breathing patterns, and of cardiovascular and cerebrovascular responses in healthy and cardiopulmonary disease individuals. Thus, answering the question posed in the title, we are still learning about respiratory and cardiovascular patterns from respiratory exercise programs.

\section{Mailing Address: Gabriel Dias Rodrigues, PhD}

Laboratory of Experimental and Applied Exercise Physiology

Fluminense Federal University, Niterói, Brazil.

Rua Professor Hernani Pires de Melo, 101. Postal Code: 24210-130, São Domingos, Niterói, RJ - Brazil.

E-mail: gabrieldias@id.uff.br 


\section{References}

1. Fetter C, Souza LA, Dartora DR, Schein A, Eibel B, Casali K, Irigoyen MC. Increased Maximal Expiratory Pressure, Abdominal and Thoracic Respiratory Expansibility in Healthy Yoga Practitioners Compared to Healthy Sedentary Individuals. Int J Cardiovasc Sci. 2021; 34(6):728-731. https://doi.org/10.36660/ijcs.20200030

2. Cramer H, Lauche R, Haller H, Steckhan N, Michalsen A, Dobos G. Effects of yoga on cardiovascular disease risk factors: a system-atic review and meta-analysis.Int J Cardiol. 2014;173(2):170-83.

3. Santaella DF, Devesa CR, Rojo MR, Amato MB, Drager LF, Casali KR, et al. Yoga respiratory training improves respiratory function and cardiac sympathovagal balance in elderly subjects: a randomised controlled trial. BMJ Open. 2011;1(1):e000085.

4. Rodrigues, G., Gurgel, J., Gonçalves, T., Soares, P. Acute effects of inspiratory loading in older women: where the breath meets the heart. Respir Physiol. Neurobiol.2020; 26 (285), 1035-1089.

5. Rodrigues G, Gurgel J, Galdino I, da Nóbrega AC, Soares PP (2020) Respiratory pump contributions in cerebrovascular and postural control responses during orthostatic stress in older women. Respir Physiol Neurobiol .2020;275:1033-84.

6. Rodrigues G D, Gurgel J L, Goncalves TJ, Silva Soares PP. Inspiratory muscle training improves physical performance and cardiac autonomic modulation in older women. Eur J Appl Physiol.2018;118:1143-52.

7. Rodrigues GD, Dal Lago P, Soares PPS. Time-dependent effects of inspiratory muscle training and detraining on cardiac autonomic control in older women. Experim Eerontol.2021;150.222357.

8. Rodrigues GD, Dal Lago P, Soares PPS. Inspiratory muscle training improves breathing pattern and sympatho-vagal balance but not spontaneous baroreflex sensitivity in older women. Respir Physiol Neurobiol.2021;290:103672.

9. Rodrigues G, Gurgel J, Galdino I, Nobrega AC, Soares P. Inspiratory muscle training improves cerebrovascular and postural control responses during orthostatic stress in older women. Eur J Appl Physiol.2020;120:2171-81. 